\title{
Políticas migratorias de control y protección en tiempos del COVID-19
}

\author{
Migration-Control and Migration-Protection \\ Policies in Times of COVID-19
}

\author{
Eduardo Torre-Cantalapiedra \\ El Colegio de la Frontera Norte, México
}

\begin{abstract}
Resumen
El objetivo de este trabajo es analizar los cambios y continuidades en las políticas de control de las migraciones irregulares y de protección a los migrantes en Estados Unidos y México durante la pandemia del COVID-19, teniendo en cuenta que su mayor referente fue la migración procedente de los países del Norte de Centroamérica. Adicionalmente, se examina cómo la emergencia sanitaria ha afectado a los migrantes centroamericanos en origen, tránsito y destino. La política de control fue instrumentalizada por el gobierno de Donald Trump para avanzar en su agenda antiinmigrante, mientras que México siguió priorizando las políticas de contención sobre las de protección. Para legitimar sus acciones en la materia migratoria los gobiernos de ambos países han alimentado el discurso que señala a la migración como riesgo para la salud pública.
\end{abstract}

Palabras clave: Estados Unidos, México, migración centroamericana, políticas migratorias, protección internacional.

\section{Abstract}

The objective of this work is to analyze the changes and continuities in the policies to control irregular migration and to protect migrants in the United States and Mexico during the COVID-19 pandemic, considering that its main reference was migration from of the countries of the North of Central America. Additionally, it examines how health emergency has affected Central American migrants in origin, transit, and destination. The pandemic was instrumentalized by the government of Donald Trump to deploy its anti-immigrant agenda, while Mexico continued to prioritize containment policies over protection policies. To legitimize their actions on migration issues, the governments of both countries have fed the discourse that points to migration as a risk to public health.

Key words: United States, Mexico, Central American migration, international protection, migration policies.

Artículo recibido el 31 de marzo de 2021 y aprobado el 26 de abril de 2021. 


\section{INTRODUCCIÓN}

$\mathrm{E}$ 11 de marzo de 2020, tras el incremento acelerado de casos graves de la enfermedad causada por el virus COVID-19 en el mundo, la Organización Mundial de la Salud (OMS) declaró la situación como pandemia. La enfermedad causa infecciones respiratorias de diferente gravedad y se transmite con gran facilidad, lo que de acuerdo con los datos de la Universidad Johns Hopkins (2021) se había traducido en más de 110 millones de casos a lo largo de todo el mundo y en más de 2.6 millones de muertes a un año desde que se declarará la emergencia sanitaria. Con insuficiente información para responder al fenómeno de estas características, los gobiernos de los diferentes países han adoptado por prueba y error diversas medidas para tratar de prevenir o limitar la propagación del virus en sus territorios afrontando escenarios contrastantes: con brotes de diferente dimensión y transmisión en comunidad.

Aunque muchas de las medidas tomadas por las democracias liberales han tenido resultados exiguos a la hora de frenar la expansión del COVID-19, lo cierto es que la combinación del aislamiento en los hogares, las cuarentenas y el distanciamiento han mostrado cierta eficacia para mitigar sus adversas consecuencias (Ferguson et al., 2020). Asimismo, la movilidad internacional ha sido drásticamente reducida con el cierre de fronteras, restricciones de entrada, cambios en los requisitos de las visas y/o entrada, (OIM, 2020), pues se ha considerado que los intensos movimientos de población, especialmente el turismo y los viajes de negocios, han sido factores clave a la hora de expandir globalmente el coronavirus (Guadagno, 2020). ${ }^{1}$ Según ACNUR, hasta 167 países cerraron sus fronteras - total o parcialmente- para detener el contagio del COVID-19 (Cárdenas, 2020). Por ejemplo, México y Estados Unidos acordaron una restricción temporal de los viajes no esenciales a lo largo de la frontera que comparten, lo que redujo drásticamente el volumen de cruces a través de los diferentes puertos de entrada oficiales. A pesar de que la pandemia no debe ser atribuida a las migraciones (Banulescu-Bogdan et al., 2020), se acumula evidencia de que las políticas migratorias han sido creci-

1 Algunos modelos han sido propuestos para explicar la manera en que se produce la difusión del COVID-19 entre los países a través de los movimientos poblacionales (Sirkeci y Yüceşahin, 2020). 
entemente restrictivas e insolidarias, esgrimiendo razones sanitarias y de salud pública (Adamski, 2021; Sanchez y Achilli, 2020).

El objetivo de este trabajo es analizar los cambios y continuidades acaecidos en las políticas de control de las migraciones irregulares ${ }^{2}$ y de protección a los migrantes en Estados Unidos y México tras un año desde que se declarara la pandemia del COVID-19, teniendo en cuenta que su mayor referente fue la migración procedente de los países de Guatemala, Honduras y El Salvador, el denominado Norte de Centroamérica (NCA). Para el logro de este objetivo, primero, se analizan sucintamente los efectos que la emergencia sanitaria ha tenido sobre los migrantes centroamericanos en origen, tránsito y destino. Esto permite ponderar los importantes retos que, en términos de gestión migratoria, enfrentaron los gobiernos estadounidense y mexicano en los diferentes momentos del desarrollo de la pandemia. Segundo, se examinan los conceptos del análisis: control, protección y externalización de fronteras. Tercero, se presenta sucintamente el panorama de políticas migratorias de Estados Unidos y México antes de la pandemia. Cuarto, con base en la revisión bibliográfica y hemerográfica pertinentes, la revisión documental, el análisis de datos administrativos - de la Patrulla Fronteriza de Estados Unidos, del Instituto Nacional de Migración (INM), de la Comisión Mexicana de Ayuda a Refugiados (Comar), de la Unidad de Política Migratoria, Registro e Identidad de Personas (UPMRIP) y de la Secretaría de Gobernación (Segob) - se analizan las acciones, medidas y discursos en materia migratoria de Estados Unidos y México durante el primer año de la emergencia sanitaria.

\section{MIGRANTES CENTROAMERICANOS: VULNERABILIDAD EN ORIGEN, TRÁNSITO Y DESTINO}

Aunque durante los primeros meses de la pandemia la migración centroamericana hacia Estados Unidos se redujo sustancialmente, esta movilidad no llegó a detenerse y paulatinamente ha ido reactivándose con el paso del tiempo, incluyendo varios intentos de avanzar en caravanas. La razón fundamental es que las consecuencias subyacentes de la migración no solo se mantienen - la falta de oportunidades económicas, la pobreza, las diferentes clases de violencia, las razones familiares, entre otras-, sino que la emergencia sanitaria las agrava.

2 Se debe hacer notar que la condición de irregularidad es generada por los Estados a través de sus políticas y leyes. 
La crisis del COVID-19 ha derivado en una crisis económica, social y política, así mismo, ha desprotegido a los sectores más desfavorecidos - los de menos recursos, pero también a una parte de quienes alcanzan ingresos medios- (Cepal, 2020).

La difícil situación de muchas familias centroamericanas se vio agravada por dos factores: 1) que muchos migrantes dejaron de enviar remesas a sus países de origen y 2) los huracanes Eta e Iota, que tuvieron cerca de cuatro millones de damnificados en Honduras y que se estima condujeron a un incremento del diez por ciento del nivel de pobreza (Naciones Unidas, 2020; Tucker y Pindado, 2020).

Tampoco puede descartarse que, tras un cierto periodo de flujos migratorios reducidos debido a la pandemia del COVID-19 y a las políticas migratorias durante la misma, se generen contingentes más voluminosos en el futuro - un efecto que pudo observarse tras los efectos inhibitorios en los flujos de la puesta en funcionamiento del Programa Frontera Sur en 2014 o la llegada la presidencia estadou nidense de Donald Trump en 2017- (Isacson et al., 2020). Algunos medios de comunicación han augurado un boom en los flujos migratorios para este mismo año, pues de acuerdo con las estadísticas de la patrulla fronteriza en febrero de 2021 se superaron las $100 \mathrm{mil}$ aprensiones (Arroyo, 2021). Además, el hecho de que surgieran varias ca ravanas de migrantes tras los meses iniciales de la pandemia pone de manifiesto que son muchos los migrantes de bajos recursos que están a la expectativa de tener una oportunidad para emprender el camino hacia el norte. ${ }^{3}$ Por lo tanto, no solo es relevante tener en cuenta el incremento de los volúmenes, sino los perfiles sociodemográficos de quienes integran estas movilizaciones.

Los migrantes centroamericanos en tránsito, al igual que otras poblaciones migrantes que cruzan por México, son altamente susceptibles de contagiarse de distintas enfermedades por dos razones: pri mero, los migrantes y refugiados son una población altamente móvil lo que implica incrementar las oportunidades de entrar en contacto y estar expuestos a personas afectadas con enfermedades respiratorias como el COVID-19 (Brito, 2020). Segundo, el hecho de que deban

3 Las investigaciones sobre las caravanas han dado cuenta de que el perfil socioeconómico de las personas que mayormente integran tales marchas es el de personas de bajos o muy bajos recursos (El Colef, 2018). Caravanas de migrantes es el término empleado para referir a grupos conformados por un gran número de migrantes que deciden realizar sus travesías hacia el norte juntos; las que tuvieron un volumen de participación más alto son las que a finales de 2018 partieron de Honduras y El Salvador (Torre y Mariscal, 2020). 
pasar cierto tiempo en ciudades de la frontera norte, en las que convergen diferentes grupos de migrantes, ${ }^{4}$ deriva en que los migrantes residan en albergues y recintos en condiciones de insalubridad y hacinamiento que facilitan la transmisión de este tipo de enfermedades. Entre ellas Tijuana, la ciudad más afectada por el COVID-19 en Baja California - tercer estado con el mayor número de casos de México-, donde bajo circunstancias normales los migrantes residen en condiciones muy precarias y están expuestos a la violencia, ahora debe sumarse el riesgo al contagio del COVID-19 (Blue et al., 2021; Mckee y Del Monte, 2020). Bojórquez et al., (2020) muestran cierta evidencia cuantitativa que apunta a que los migrantes y solicitantes de asilo en México tienen un mayor riesgo de contraer enfermedades respiratorias como el COVID-19, teniendo en cuenta la edad y sexo, así como las condiciones de riesgo subyacentes.

El destino al que aspiraban la mayoría de los migrantes centroamericanos era Estados Unidos, donde los que ya residen en aquel país han sido una pieza clave de la fuerza de trabajo esencial bajo la circunstancia del COVID-19. Los migrantes - regulares e irregulares-se han desempeñado como trabajadores en el sector salud, la agricultura, el procesamiento de alimentos, los transportes, etcétera; el valor de la mano de obra migrante en algunos sectores fue implícitamente reconocido por el presidente Trump al exentar a trabajadores estacionales y de agricultura de su prohibición migratoria (Hollifield, 2020). No obstante, la población migrante ha sido considerada como vulnerable (Gelatt, 2020; Velasco et al., 2020). La crisis socioeconómica derivada de la situación de emergencia sanitaria ha afectado en mayor medida a los migrantes en situación irregular, pues se encuentran en la informalidad y son los primeros en perder sus empleos (Naciones Unidas, 2020). Asimismo, estos migrantes no disponen de la protección social de la que sí gozan el resto de los trabajadores y carecen de seguros médicos o tienen un acceso más limitado a los mismos (Cleaveland y Waslin, 2021; Ramírez-García y Lozano, 2021). Además, la situación de irregularidad, tanto en el tránsito como en el destino, implica que los migrantes sean reticentes a acudir a los centros de sa-

$4 \quad$ En las ciudades de frontera convergen diferentes grupos de migrantes extranjeros, entre ellos 1) los que pretenden iniciar el proceso solicitud de asilo; 2) los que fueron devueltos por las autoridades estadounidenses de acuerdo con los Protocolos de Protección a Migrantes (MPP), que según este programa deben esperar en México durante la sustanciación de sus procesos ante los tribunales; y 3) los migrantes que desde el mes de marzo fueron retornados de manera forzada y expedita de Estados Unidos de acuerdo con el Título 42. 
lud en caso de presentar síntomas de la enfermedad, por miedo a que las autoridades los detengan y deporten (Bonilla y Tovar, 2020; María Dolores Palencia entrevistada en Valle y Deschak, 2021).

Como se puede apreciar, la situación de pandemia del COVID-19 ha requerido de grandes dosis de solidaridad con los migrantes centroamericanos en origen, tránsito y destino. En cuanto a los migrantes que han estado llegando tras la declaración de la pandemia, hay que tener en cuenta que muchos de ellos estarían necesitados de protección internacional, pues huyen de una violencia que les hace encajar en la definición de refugiado de acuerdo con Convención de Ginebra de 1951, escapan de la catástrofe generada por los huracanes que les hace "refugiados climáticos", entre otros.

\section{CONCEPTUALIZACIÓN DE LAS POLÍTICAS MigRATORIAS DE CONTROL Y PROTECCIÓN}

A la hora de entender cómo los países gestionan los flujos migratorios durante la situación de pandemia de COVID-19, dos facetas de las políticas migratorias adquieren una mayor trascendencia política: el control de la migración irregular y la protección de los derechos humanos de los migrantes. Se denomina políticas de control a aquellas normas y actuaciones de los Estados que tienen por objeto controlar y ordenar los flujos migratorios de entrada y permanencia de los migrantes en sus respectivos territorios. En lo que respecta a los flujos migratorios irregulares los países establecen barreras materiales y humanas para tratar de impedir que los migrantes se internen en su territorio sin cumplir las normas de entrada que estos establecen, y al interior del territorio se establecen una serie de controles, redadas, un sistema de deportación, entre otros mecanismos que pretenden reducir la cifra de inmigrantes irregulares que se encuentran al interior del territorio del país. En los últimos años estas políticas de control se han endurecido en muchos países, en parte favorecidas por las representaciones negativas que existen sobre los migrantes (Arango, 2019).

Además, algunos países promocionan y presionan para que países emisores y/o de tránsito de migrantes, lleven a cabo políticas migratorias de acuerdo con sus intereses particulares - por ejemplo, el control de los flujos o que acepten ser terceros países seguros-; en lo que la literatura académica ha denominado externalización de las políticas migratorias o externalización de fronteras (Garibo, 2016; Naranjo, 2014). 
Por otro lado, las políticas migratorias de protección son aquellas cuyo propósito elemental es la protección y defensa de los derechos humanos de los migrantes - particularmente, en cuanto a la vida y a la integridad física - ante las transgresiones de tales derechos en los países de origen, tránsito y destino (Torre, 2021). Un ejemplo de esta clase de políticas migratorias lo constituyen los mecanismos de protección internacional (asilo, refugio, entre otros) existentes en numerosos países y otro lo constituyen las Tarjetas de Visitantes por Razones Humanitarias (TVRH) en México. Así cuando una persona vive en un país que no puede o no pretende garantizar los derechos humanos a sus ciudadanos, una de las maneras para lograr protegerlos, sería migrar internacionalmente a un país que haya asumido el compromiso de la proveeduría de tales derechos en sustitución de aquel (Betts, 2013).

Ambos tipos de políticas migratorias constituyen sendos ejercicios de soberanía que pueden resultar en contradicción, por un lado, el control de sus fronteras y decidir quién entra o no en su territorio, por otro lado, la adquisición de obligaciones legales de respetar los derechos humanos de los migrantes - se sigue en este punto un argumento similar al realizado por Bustamante, (2002: 168) y siguientes-. En este sentido, cabe señalar el Consejo de Derechos Humanos de Naciones Unidas exhortó a que las políticas migratorias sean compatibles con las obligaciones impuestas a los Estados por el derecho internacional de los derechos humanos, adoptando medidas que entre otras promuevan y protejan los derechos humanos de todos los migrantes con independencia de su situación migratoria - e incluyendo a quienes se encuentran en tránsito- (Naciones Unidas, Asamblea General, 2015).

Si bien por motivos analíticos en este trabajo se hace una distinción entre políticas migratorias de control y de protección, así como para dar cuenta de la necesidad de desarrollar instrumentos que permitan proteger a los migrantes - especialmente en determinados contextos y circunstancias en las cuales sus derechos son vulnerados-, se debe señalar que: primero, las políticas que aquí son denominadas de protección también pueden ser observadas como de control u por otra de sus facetas (por ejemplo, la integración); y viceversa. De hecho, las que en aquí son observadas como políticas migratorias de protección, 
en otras investigaciones son consideradas como políticas de control. ${ }^{5}$ Segundo, clasificar y analizar una cierta política como de protección no quiere decir necesariamente que sean efectivas a la hora de proteger a los migrantes.

\section{SituACión DE LAS POLÍTICAS MigRATORIAS ANTES DE LA PANDEMIA}

\section{Estados Unidos: reducir la inmigración irregular y el derribo del sistema de asilo}

Al menos desde la década de los noventa, las políticas migratorias de gobiernos demócratas y republicanos han coincidido en la pretensión de reducir y disuadir la inmigración irregular, que llega hasta el territorio estadounidense, a través de la militarización de su frontera sur y el desarrollo de un sistema de deportación que criminaliza a los migrantes (Argueta, 2016; Capps et al., 2019). Sobre esta base sólida de medidas que se han acumulado en contra de la inmigración irregular, el gobierno del presidente Trump desarrolló una amplia agenda en contra de los migrantes, no solo para reducir los flujos migratorios irregulares, también con el objetivo de disminuir la inmigración regular y suprimir las diferentes herramientas de las que dispone Estados Unidos para proteger a los migrantes - como son el asilo y otras formas de protección humanitarias temporales-. La administración de Trump consideraba que el grueso de los solicitantes de asilo empleaba este instrumento legal para ganar acceso al territorio estadounidense de manera fraudulenta. Entre otras medidas emprendidas se puede señalar: la dedicación de más medios materiales y humanos para el control fronterizo, la aprobación de cambios legales para incrementar las deportaciones al interior del territorio, las presiones realizadas a otros países para que realicen las políticas de contención migratoria o firmasen acuerdos de tercer país seguro, la limitación de la cifra de personas que obtienen protección internacional cada año, la interposición de todo tipo de trabas a quienes llegaban al territorio estadounidense para solicitar asilo, entre otras.

La presidencia de Trump se parapetó en diversos sucesos acaecidos desde mediados de su mandato para lograr y legitimar sus

5 Ver por, ejemplo Arango, 2005, en cuanto a la figura del asilo; Basok, 2020, en cuanto a las TVHR. 
metas de restringir y reducir la migración, que no se hubieran alcanzado bajo otras circunstancias. Por un lado, el fenómeno de las caravanas de migrantes (desde finales de 2018) y el auge de los flujos migratorios centroamericanos en 2019 -especialmente notables en mayo de dicho año-, sirvieron de excusa para reforzar el control fronterizo, al interior del territorio y dificultar el proceso de solicitud de asilo en aquel país: aumentar los periodos de espera a través del mecanismo del metering o la regulación del número de migrantes que pueden solicitar asilo - que ya fue implementado por la administración de Barack Obama-; la creación y expansión de los Protocolos de Protección a Migrantes (MPP, por sus siglas en inglés) que implica que los migrantes fueran devueltos a México mientras eran procesados sus casos en las cortes de justicia estadounidenses; la prohibición de solicitar asilo si no se ha realizado anteriormente una solicitud de protección en un país de tránsito, entre otras. Por otro lado, —como se analizará más adelante-, la agenda antiinmigrante de Trump se ace lera y robustece durante la emergencia sanitaria del COVID-19 bajo el pretexto de la salud pública y de la creciente crisis económica (Pierce y Bolter, 2020).

En el plano discursivo cabe mencionar que la administración Trump mantuvo un discurso xenófobo con tintes racistas que criminalizaba a los migrantes. De este modo promovieron una imagen muy negativa de los migrantes que pretende hacer ver a sus políticas restrictivas y persecutorias como necesarias. Por ejemplo, ante la llegada de las caravanas, el presidente y diversos funcionarios de alto rango del gobierno estadounidense mantuvieron un discurso que criminalizaba tales marchas y a sus integrantes.

\section{México: la contención del tránsito y un sistema de refugio disfuncional}

La literatura académica referente a las políticas migratorias respecto a los flujos migratorios en tránsito por el territorio mexicano ha coincidido en señalar: 1) que al menos desde la década de los noventa, los sucesivos gobiernos de México - con independencia de su adscripción partidista- han desplegado una política de contención que implica la detención y deportación de migrantes tanto a nivel fronterizo como a lo largo de todo el territorio nacional; 2) que estas políticas de contención están asociadas con mayores abusos y agresiones en contra de los migrantes perpetrados tanto por agentes delincuenciales como por 
agentes estatales; y 3) que tales políticas son en cierta medida producto de la influencia y presiones estadounidenses en el desarrollo de las mismas (Anguiano y Lucero, 2020; Calva y Torre, 2020; París Pombo, 2016; Yee y Torre, 2016).

La administración de Trump presionó a México y a los países centroamericanos para que realizaran labores de contención de los flujos migratorios procedentes de Centroamérica. ${ }^{6}$ En 2019, teniendo como telón de fondo la llegada de Andrés Manuel López Obrador a la presidencia, el fenómeno de la emergencia de caravanas de migrantes, el incremento de los flujos migratorios llegando a Estados Unidos - especialmente el mes de mayo- y el cambio de presidencia en México, el gobierno estadounidense presionó a su homólogo mexicano mediante una subida arancelaria si no lograban controlar los flujos migratorios que transitaban hacia Estados Unidos (Calva y Torre, 2020). Mediante un "acuerdo" de cooperación —en realidad, la imposición del gobierno estadounidense- tras las amenazas de los aranceles en mayo de 2019, México se comprometía a aumentar las fuerzas de seguridad destinadas al control de las fronteras del territorio mexicano y al interior de país, expandir la colaboración con los MPP, colaborar en materia del combate del tráfico de personas, entre otras (U.S. Department of State, 2019).

En contraste con las políticas de contención, desde la década de 2010 se produce una renovación de los instrumentos de protección. De acuerdo con Ley sobre Refugiados, Asilo Político y Protección Complementaria de 2011, los extranjeros que se encuentren en territorio mexicano tienen el derecho a solicitar el reconocimiento de la condición de refugiado. Sin embargo, la cifra de quienes han obtenido refugio en México es reducida, en parte, porque en la práctica concurren una serie de barreras generadas por las propias autoridades mexicanas; que llevan a cabo diversas actuaciones de bloqueo y disuasión que dificultan, o incluso impiden, alcanzar la condición de refugiado (o en su caso, la protección complementaria) (Torre et al., 2021).

Por otra parte, de acuerdo con el art. 52-V de la Ley de Migración (LM) las personas extranjeras podrán permanecer en territorio nacional bajo la condición de estancia Visitante por Razones Humanitarias en los siguientes supuestos: a) ser ofendido, víctima o testigo de algún

6 Aunque existen flujos migratorios que atraviesan por México y Centroamérica hacia Estados Unidos procedentes de otros países de Latinoamérica y del mundo, estos tres países siguen siendo los más relevantes en términos cuantitativos (al respecto ver datos sobre detenciones en Segob et al., 2021). 
delito cometido en territorio mexicano; b) ser niña, niño, adolescente migrante no acompañado; c) ser solicitante de asilo político, refugio o de protección complementaria en México (LM, 2017, art. 52-V, párrafos a, b y c). Además de estos casos pautados, el último párrafo del art. 52-V de la LM, permite otorgar esta condición:

A los extranjeros que no se ubiquen en los supuestos anteriores, cuando exista una causa humanitaria o de interés público que haga necesaria su internación o regularización en el país (LM, 2017, art. 52-V, último párrafo).

El Reglamento de la Ley de Migración (RLM) señala varias de las situaciones que califican como causa humanitaria:

a. Exista riesgo a su salud o vida propias y requiera permanecer en el territorio nacional.

b. Tenga en el territorio nacional a un familiar directo bajo custodia del Estado y sea necesaria su autorización para prestarle asistencia médica, psicológica, o bien, su intervención para reconocimiento o recuperación de cadáver.

c. Requiera asistir a un familiar directo en estado grave de salud que se encuentre en el territorio nacional (RLM, 2014; art. 137IV).

"La persona... que por su situación de vulnerabilidad no pueda ser devuelto a su país de origen, o no pueda continuar su viaje" (RLM, 2014, art. 63-III).

La emisión TVRH tuvo un importante auge al momento de la atención de las caravanas de migrantes de finales de 2018 y comienzos de 2019, pues se pusieron en marcha diversos programas especiales de emisión de este tipo de documentos, algo que no tuvo continuidad tras las amenazas de los aranceles.

Aunque, el discurso de la administración de López Obrador está basado en la no discriminación, la empatía y el respeto de los derechos humanos de los migrantes, en la práctica se produjo un recrudecimiento de la política migratoria mexicana (Ávalos y Celecia, 2020); incluyendo polémica designación de la Guardia Nacional a las tareas de contención migratoria. 


\section{Políticas MigRATORIAS EN MEDIO DE UNA PANDEMIA}

\section{Estados Unidos: el despliegue completo de la agenda antiinmigrante}

El 20 de marzo de 2020, con base en dos disposiciones de la Public Health Service Act de 1944, —codificadas en el Título 42 del U.S. Code - que permiten bloquear la entrada de ciudadanos extranjeros que representen un riesgo para la salud pública, el director de los Centros para el Control y la Prevención de Enfermedades (CDC, por sus siglas en inglés) ordenaba la expulsión de todos los migrantes en situación irregular a México (o Canadá) —según el caso-o a sus países de origen de un modo expedito (U.S. DHHS, CDC, 2020). Así de marzo a diciembre de 2020 se produjeron cerca 400 mil devoluciones hacia México sin importar la nacionalidad de los migrantes (U.S. Customs and Border Protection, 2020a; 2020b). Los migrantes centroamericanos devueltos a México se ven orillados a esperar en ciudades fronterizas con altas tasas de delincuencia (como Tijuana o Ciudad Juárez que encabezan los listados de las ciudades más violentas del mundo) y altas prevalencias del COVID-19, donde, como se señaló, confluyen varios grupos de migrantes necesitados, lo que desborda los mermados apoyos que las organizaciones de la sociedad civil (OSC) pudieron dar debido a la pandemia (Heyman y Slack, 2018; Mckee y Del Monte, 2020).

En contraste con la búsqueda del férreo bloqueo de los flujos que entraban en Estados Unidos, las autoridades estadounidenses no tuvieron reparos en continuar con las deportaciones de migrantes. Diversas OSC - Amnistía Internacional, OXFAM, entre otras- solicitaron al gobierno de aquel país detener de manera inmediata todas las deportaciones, debido a la multitud de problemas que implica el sistema de deportación en el esparcimiento del COVID-19, los riegos para las personas bajo detención y los riesgos que las propias autoridades estadounidenses han reconocido que tienen los viajes internacionales (Amnistía Internacional et al., 2020a). Se han reportado más de cien casos en los que se deportaron personas que dieron positivo en COVID-19, por lo tanto, poniendo en riesgo a las personas en estos procesos de expulsión y produciendo la propagación de la enfermedad a los países de origen, en algunos casos, con sistemas de salud ampliamente deficitarios (Amnistía Internacional et al., 2020a; Bleiker, 
2020). Los países del NCA tienen algunos de los sistemas sanitarios más precarios de la región y no disponían de medios para enfrentar adecuadamente una crisis sanitaria como la del COVID-19, por los que sus redes de hospitales se vieron repetidamente saturadas y colapsadas (Arévalo, 2021; Barrios, 2021; Irías et al., 2021).

Existe consenso respecto a que una de las medidas más importantes que los gobiernos pueden tomar para evitar la expansión del COVID-19 es limitar las detenciones (Amnistía Internacional et al., 2020b). Aunque el Servicio de Control de Inmigración y Aduanas (ICE, por sus siglas en inglés) ajustó y limitó la aplicación de la ley en el interior del país durante la pandemia, continúo deteniendo a decenas de miles de inmigrantes en todo el país, lo que conlleva el hacinamiento de los migrantes y les impide cumplir con las normas sanitarias de distanciamiento social. Un estudio proyectó que, con las elevadas poblaciones encerradas en las instalaciones de ICE, cuanto menos 72 por ciento de los individuos estarían infectados en 90 días (Irvine et al., 2020). Las autoridades no hicieron nada por liberar a los inmigrantes de la detención, hasta que en marzo de 2020 fueron presentadas demandas judiciales exigiendo que los inmigrantes vulnerables fueran puestos en libertad, tras lo cual el ICE redujo su población detenida de 39 mil a 25 mil entre febrero y junio del 2020 (Pierce y Bolter, 2020). Lo que no impidió que fueran miles los contagiados por el COVID-19 mientras se encontraban bajo custodia de las autoridades estadounidenses, así a finales de junio de 2020 de 10 mil 513 pruebas de COVID-19 realizadas a migrantes en los centros de detención dos mil 675 resultaron positivas (Pierce y Bolter, 2020).

Las detenciones y expulsiones inmediatas de quienes cruzan de manera irregular a Estados Unidos de acuerdo con el Título $42 \mathrm{im}$ plicó el rechazo generalizado de las solicitudes de asilo; el ya mermado y vilipendiado sistema de asilo estadounidense recibía así el golpe definitivo, lo que significaba su total inoperancia al menos temporalmente. Todo ello en total contradicción con lo señalado por los organismos internacionales:

Imponer una medida general para impedir la admisión de refugiados o solicitantes de asilo, o de personas de una nacionalidad o nacionalidades determinadas, sin pruebas de un riesgo para la salud y sin medidas de protección contra la devolución, ${ }^{7}$ sería discriminatorio y no cumpliría las

7 La devolución o refoulement refiere en este caso a devolver a una persona a un país en el que correría peligro de ser perseguido por su raza, religión, nacionalidad o pertenencia 
normas internacionales, en particular en lo que respecta al principio de no devolución (ACNUR, 2020: 2).

Esta política de rechazar las solicitudes de asilo en la frontera no es coherente con otras medidas adoptadas en respuesta al COVID-19, la administración Trump ha dejado intactos viajes fronterizos que suponen una amenaza mucho mayor para la propagación del virus que los solicitantes de asilo procesados y detenidos; se prohibieron solo los viajes no esenciales por vía terrestre, pero no el resto de los viajes turísticos que se hacen por avión o barco (Guttentag, 2020). La incoherencia y la contradicción en cuanto a las diferentes políticas respecto a la movilidad humana llevadas a cabo por Estados Unidos en tiempos del COVID-19, son claves para evidenciar que tal gestión de la movilidad responde en muchos casos más a intereses políticos y económicos que sanitarios.

Para los solicitantes de asilo devueltos a México bajo el programa MPP, la situación se complicó durante la emergencia sanitaria. Los migrantes y sus abogados tuvieron que afrontar una falta de claridad sobre cuándo deben presentarse ante los tribunales estadounidenses (Pachico y Meyer, 2020). Las audiencias judiciales de los migrantes que participaron en este programa se vieron pospuestas en repetidas ocasiones (Eller et al., 2020; Slack y Heyman, 2020).

El discurso que pretenden legitimar políticas migratorias por razones sanitarias señalaba a los migrantes como un riesgo para la salud pública estadounidense. Sin embargo, no se aportaba ninguna prueba de que los migrantes llegados a la frontera comportaran un riesgo relevante - posiblemente mucho menor al que comportan otros flujos- y además se omite que Estados Unidos era uno de los focos más importantes de la pandemia en América y en el mundo (Isfer, 2020). En algunos casos, las autoridades estadounidenses han favorecido de manera muy burda la construcción del migrante como riesgo para la salud pública. Un comunicado de la Patrulla Fronteriza del Sector de San Diego señalaba que fortalecería su presencia a lo largo de la costa de California para frenar el tráfico de personas y narcotráfico, al mismo tiempo que dicho esfuerzo ayudaría a prevenir que posibles nuevos casos del COVID-19 entren en nuestras comunidades (CBP, 2020).

a un grupo social particular u opinión política. El principio de no devolución o non-refoulement es un principio del derecho internacional que prohíbe la realización de esta práctica. 
En otras palabras, que detener la migración es contener la proliferación del COVID-19.

\section{México: contención en sus acciones y discursos}

Al igual que en el caso de Estados Unidos y como la atestiguan las cifras de devoluciones realizadas por el INM, México no dejó de detener y deportar a migrantes durante la emergencia sanitaria, aunque todo el proceso supusiera un riesgo para la salud de los migrantes y este tipo de acciones pudieran coadyuvar a la expansión de la enfermedad (Figura 1). Si bien es cierto que se produce una disminución especialmente pronunciada en los meses de abril a julio de 2020, esta se debe más al descenso de los flujos migratorios que sucedió durante los meses subsiguientes a la declaración de la pandemia que a las medidas que las autoridades pudieran tomar para revertir sus acciones para contener la migración. Como puede observarse en la Figura 1, a partir del mes de agosto, ante la reavivación de los flujos migratorios centroamericanos, las cifras de deportaciones realizadas por México, aunque lejos de los volúmenes de deportaciones del año 2019 cuando el gobierno de López Obrador realizó una contención especialmente vigorosa tras las amenazas arancelarias en un contexto con altos volúmenes de migrantes en tránsito.

Figura 1. Monto mensual de eventos de migrantes del NCA devueltos a sus países de origen, enero 2017-febrero 2020

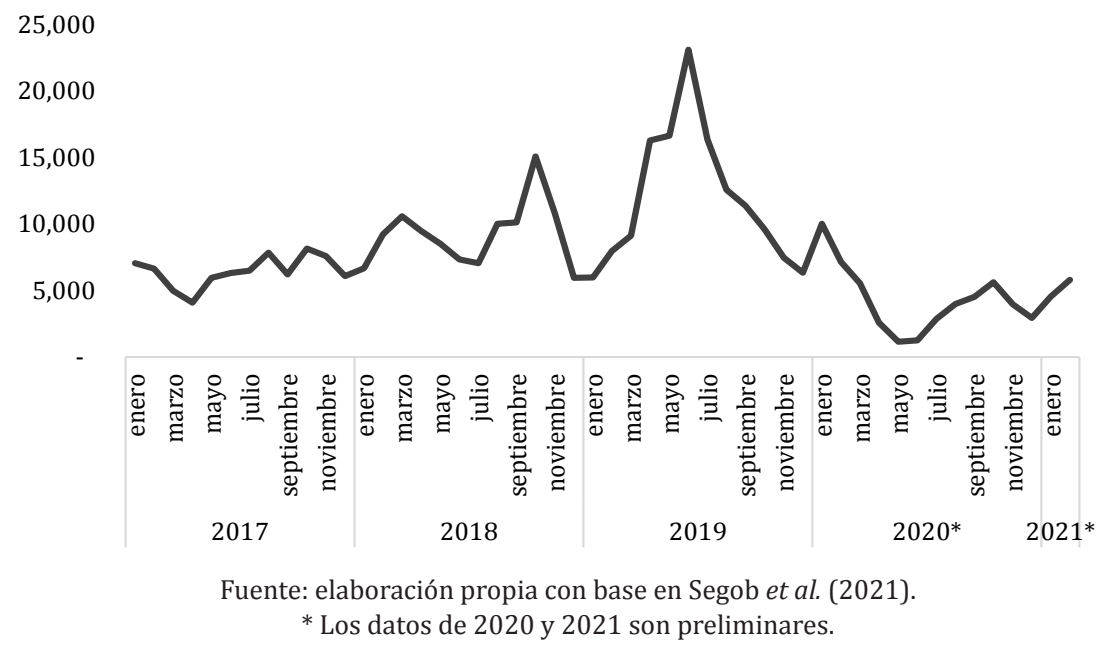


La continuidad del sistema de deportación implica que miles de migrantes estuvieran privados de su libertad en centros de detención en los que se favorece el contagio de COVID-19. La situación ameritaba liberar a los migrantes - especialmente, a los más vulnerables-y adecuar las instalaciones a la situación sanitaria. Al igual que sucedió en Estados Unidos, las medidas de liberación en los centros de detención y de adecuación a las instalaciones se produjeron tras que diversas OSC presionaran al gobierno tanto mediante manifiestos, declaraciones públicas y sobre todo a través de demandas judiciales. Un juez de la Ciudad de México ordenó liberar a aquellas personas que de acuerdo con los estándares de la Secretaría de Salud se consideran vulnerables ante la pandemia, incluyendo, entre otras a mayores de 60 años y personas con alguna enfermedad crónica (Becerril, 2020). Además, las autoridades judiciales ordenaron al INM cumplir con los protocolos de salud pública en los centros de detención (Khuner, 2020).

La respuesta que el gobierno mexicano dio a las caravanas de migrantes durante la pandemia son reveladoras del predominio de la contención en la respuesta de México a la migración centroamericana en dicho periodo. En enero de 2020, más de un mes antes de que se detectara el primer caso de COVID-19 en México, ante la llegada de una caravana de migrantes procedente de San Pedro Sula (Honduras), el gobierno mexicano realizó un gran despliegue de fuerzas de seguridad para detener a los participantes en tal marcha, incluyendo a varios miles de integrantes de la Guardia Nacional. Este es el recibimiento que presumiblemente les esperaba a las caravanas durante la pandemia. Aunque, las dos caravanas que salieron de San Pedro Sula finalmente serían bloqueadas por las autoridades guatemaltecas antes de que lograsen alcanzar el territorio mexicano, resulta relevante analizar las actuaciones y el discurso del gobierno de México respecto a las mismas. ${ }^{8}$

8 El 30 de septiembre de 2020 partió de San Pedro Sula (Honduras) la primera marcha en tiempos de pandemia. A diferencia de caravanas anteriores que no tuvieron excesivas trabas en su tránsito por Guatemala, ya que los migrantes hondureños pueden desplazarse libremente por el territorio de aquel país portando sus documentos de identidad nacional - debido al convenio CA-4-, con ocasión de la pandemia se les exigía portar una prueba de coronavirus negativa para ingresar al territorio guatemalteco en cumplimiento de los protocolos sanitarios del COVID-19. El gobierno guatemalteco estaba comprometido con la administración Trump a frenar la migración, en consecuencia, procedió con la deportación de más de 3,500 hondureños quienes carecían de tal prueba (Reina, 2020). Bajo el mismo argumento de la prueba de COVID-19 negativa, el 16 de enero de 2021, un grupo de migrantes hondureños — que formaban parte de una 
En cuanto a la primera de las caravanas en tiempos de pandemia, a finales de septiembre de 2020, México desplegó cientos de efectivos del Ejército Mexicano, Guardia Nacional y del INM a lo largo de la frontera con Guatemala (Peters, 2020). Está escenificación fue acompañada de la amenaza de sanciones a los integrantes de las caravanas, a los que podrían aplicarse duras sanciones -incluso de cinco a 10 años de prisión- contempladas en el Código Penal Federal y en los códigos penales chiapaneco y tabasqueño ("Gobierno advierte cárcel para migrantes que entren sin protección ante COVID-19", 2020). También de señalamientos de altos cargos, como el subsecretario de Relaciones Exteriores, Maximiliano Reyes, de que estas movilidades son potencialmente peligrosas en el marco de la emergencia sanitaria ("Caravanas migrantes, un riesgo para salud pública: SRE", 2020). Todas estas actuaciones y discursos pretenden la disuasión de los migrantes en la lógica de la contención, implican la criminalización de los migrantes cuanto menos de manera discursiva- y favorecen la asociación entre migración y riesgo para la salud pública.

En cuanto a la caravana de enero de 2021, el INM difundió un video en que mostraba a cientos de agentes en las instalaciones de Chiapas y Tabasco, así como decenas de ellos apostados en la frontera con Guatemala y señalaron en varios mensajes que el INM seguiría haciendo vigilancia en la frontera sur para procurar que la internación al país sea "segura, ordenada y regular" (INM, 2021a; 2021b). Lo que significa que México seguirá deteniendo y deportando a todos los migrantes que lleguen a su territorio sin la documentación exigida, de la cual la mayoría están sistemáticamente excluidos por carecer de escasos recursos económicos. El gobierno mexicano hizo un llamado a los países centroamericanos de que aplicaran: de manera responsable los protocolos migratorios y sanitarios localmente establecidos, a fin de evitar riesgos sanitarios derivados de la pandemia de COVID-19 para las personas migrantes y la población de las comunidades de tránsito (SRE, 2021).

Esta fue una forma poco sutil de pedir que se detuvieran los flujos migratorios alegando las razones sanitarias. Nuevamente las declaraciones respecto a las caravanas dan a entender que estas implican un problema de salud pública.

caravana de cerca de nueve mil personas que se había internado en Guatemala - fue bloqueado y dispersado por el ejército guatemalteco que empleó gases lacrimógenos y varas de madera (AFP, 2021). 
En contraste con lo anterior, algunos actores gubernamentales se manifestaron explícitamente en contra de la construcción de estas marchas como riesgo sanitario. El subsecretario de Prevención y Promoción de la Salud, Hugo López-Gatell, señaló que:

Cuando se trata de migración y salud hay que tener cuidado en mantener una visión tradicional pero científicamente errónea, sería hacer un paralelismo entre migración y riesgo sanitario para la población residente. No se trata de eso. Las 2 mil 900 personas, de la nacionalidad que sean, es improbable que sean significativamente un riesgo de salud pública para los mexicanos (López-Gatell citado en Milenio Digital, 2020).

En el marco de la pandemia, el Consejo Nacional para Prevenir la Discriminación (CONAPRED) realizó una campaña en redes sociales en contra de diferentes formas de discriminación ("Aplana La Curva De La Discriminación"), que incluyó algunos mensajes a favor de la migración y para prevenir la xenofobia, que a decir de la Secretaría de Relaciones Exteriores pretendió visibilizar el estigma social que padecen los migrantes al ser considerados "como un riesgo para la salud pública" (Cepal et al., 2020, p. 4).

Las acciones y discursos oficiales en contra de la llegada de migrantes centroamericanos fueron contradictorios con otros aspectos de la gestión de la movilidad internacional. Así, por ejemplo, México no fijó ninguna restricción en las fronteras aéreas para reducir la entrada de personas al país, alegando que México ya tiene transmisión activa del virus COVID-19 y que la incidencia que podrían tener los viajeros en casos como el de México es muy reducida (González, 2021).

Al igual que sucedió con los MPP, México aceptó tácitamente la decisión unilateral de Estados Unidos de devolver de manera expedita a migrantes centroamericanos al territorio mexicano. Los que fueron devueltos a México, se encuentran en las ciudades fronterizas (Tijuana, Ciudad Juárez, entre otras) con otros contingentes de migrantes centroamericanos: quienes esperan su turno para dar comienzo a los trámites de asilo ante las autoridades estadounidenses o los que ya dieron comienzo a los mismos, pero fueron devueltos al territorio mexicano debido al programa MPP - cuyas audiencias fueron retrasadas (Isacson, 2020). Todos estos migrantes no solo tuvieron que afrontar entornos con elevadas cifras de delitos, sino que debieron hacerlo en condiciones que dificultan guardar el distanciamiento social, por lo tanto, con un alto riesgo de ser contagiadas. 
A diferencia de Estados Unidos y otros países que dieron un "portazo" a los necesitados de protección internacional que llegaban a sus territorios, México consideró que el registro de solicitudes de refugio era una actividad esencial y que debía seguir realizándose durante la pandemia (Meer y Villegas, 2020; ACNUR México, 2020). Asimismo, fue positivo para los migrantes que las autoridades suspendieran la firma semanal a la que están sometidas todos los solicitantes mientras se resuelven sus casos (Comar, 2020).

Sin embargo, durante la pandemia se mantuvieron los problemas que tiene el sistema de refugio mexicano actual. Una de las trabas más relevantes que deben superar los solicitantes son los dilatados plazos de espera. Algo que las autoridades estarían en proceso de subsanar mediante el incremento del personal encargado de procesar las solicitudes, pero que la pandemia habría postergado (Ruiz, 2020). Mientras que las solicitudes de asilo pendientes de resolución aumentaron con la llegada de la pandemia, la suspensión de los fallos por parte de la Comar implicaba que la solución de los casos se retrasase, por lo tanto, que las esperas de los migrantes se incrementen (Khuner, 2020). Por ejemplo, de las 15 mil 468 solicitudes realizadas por migrantes hondureños en 2020, solo habían sido resueltas cinco mil 692 para finales de año (Comar, 2021).

En términos de protección, la respuesta de México no estuvo a la altura de las circunstancias no solo por las deficiencias en el sistema de refugio, sino porque no se utilizaron otros instrumentos que parecen especialmente diseñados para otorgar protección en situaciones como las de la emergencia del COVID-19, como son las TVRH. De hecho, OSC instaron al gobierno mexicano a otorgar TVRH a las personas que se encuentran en el territorio mexicano de manera irregular durante la contingencia del COVID-19 (Al Otro Lado et al., 2020). Sin embargo, la entrega de estas tarjetas a los migrantes NCA se hizo en términos restringidos a los casos tasados del art. 52 de la LM con cifras de TVRH otorgadas por el INM similares a las de 2017 (Figura 2); una situación muy diferente a la de finales de 2018 y a principios de 2019, cuando los gobiernos de Peña Nieto y López Obrador respondieron al fenómeno de las caravanas con el otorgamiento de estas tarjetas por medio de programas especiales (Torre, 2021). Como se observa en la Figura 2, en el mes de enero de 2019 se alcanzó una cifra de 11 mil 153 otorgamientos a migrantes del NCA, una cifra muy superior a todas las TVRH entregadas durante todo el año 2020 a estos tres países $(6,742)$. 
Figura 2. TVRH otorgadas por el INM a migrantes del NCA, 2017-2020

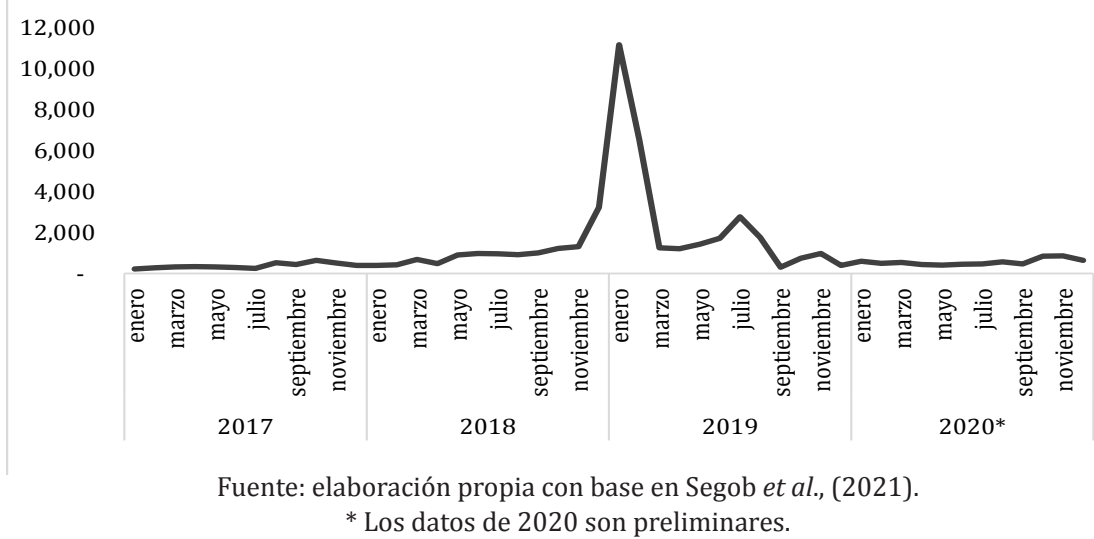

\section{COMENTARIOS FINALES}

El primer año de pandemia fue ampliamente capitalizado por el gobierno de Trump para dar un paso más en su agenda antiinmigrante a través de expulsiones expeditas hacia México de migrantes que entran en territorio de Estados Unidos de manera irregular, con independencia de si estas personas requerían de protección internacional. Además, la presión de esta administración estadounidense para que México y los países de Centroamérica realicen la contención de los flujos migratorios rindió sus frutos, así durante el periodo analizado México priorizó las políticas de control de flujos migratorios. Algo que fue especialmente evidente en el caso de las caravanas de migrantes - eventos migratorios que son especialmente mediáticos y que atraen una gran atención sobre la migración y la manera en que es gestionada por los Estados-, México desplegó diversas fuerzas de seguridad para detener tales marchas en caso de que alcanzaran su territorio.

Durante la pandemia, la contención se realizó incluso en contra de quienes buscan/requieren de protección internacional $u$ otra forma de protección humanitaria, pese a que la emergencia sanitaria justificaría una mayor solidaridad con estas personas en movilidad. Las políticas migratorias enfocadas en la protección de los migrantes de Estados Unidos - como son el asilo/refugio, las medidas humanitarias de protección temporal- fueron casi inexistentes y su sistema de asilo fue defenestrado por la aplicación del Título 42. En México las me- 
didas de protección fueron muy deficitarias: las solicitudes de refugio se mantuvieron a la par que las numerosas trabas que los migrantes enfrentan para superar con éxito el proceso y no hubo voluntad política de emplear instrumentos que hubieran otorgado alivio a miles de migrantes como, por ejemplo, las TVRH.

Además, las políticas migratorias estadounidenses y mexicanas en el primer año de la pandemia fueron incongruentes con el resto de las políticas respecto a la movilidad. Por ejemplo, se terminaron o redujeron los sistemas de protección internacional que tendrían poco impacto en la circulación del COVID-19, mientras no se impiden movilidades congran potencial para generar transmisión del virus como el turismo. Las propias políticas migratorias fueron contradictorias entre sí. Por ejemplo, se mostraba una gran reticencia y escrúpulo para las entradas de migrantes en los territorios nacionales, mientras que las aglomeraciones de migrantes en centros de detención y salidas de migrantes hacia los países de origen o los territorios de terceros países no fueron problematizadas por los gobiernos, pese a que ponen en peligro a los migrantes y el potencial de difundir la enfermedad.

Los gobiernos de los dos países buscaron legitimar sus políticas migratorias con un discurso que, explícita o implícitamente, señalaba a las migraciones -individuales, en pequeños grupos o grandes grupos (caravanas) - constituían un riesgo para la salud pública. Sin embargo, no queda demostrado que estas movilidades tengan relevancia para la transmisión del virus en el contexto de la pandemia, ni que justifiquen las actuaciones realizadas respecto a los flujos migratorios. La asociación de la migración como riesgo para la salud pública encajó en la estrategia discursiva xenófoba del gobierno de Trump, durante su mandato promovió la representación del migrante como un riesgo multidimensional - de seguridad pública, económico y de salud pública-. En el caso de la administración de López Obrador, el discurso en contra del avance de las caravanas por razones sanitarias resulta contradictorio, no solo con el discurso oficial que enfatiza la acogida de los migrantes, la empatía con los mismos y el respeto de sus derechos humanos, sino con el hecho de que otros actores de su propio gobierno hayan combatido expresamente la representación de la migración como riesgo para la salud pública.

Ante una coyuntura marcada por crisis profundas en los países del NCA, la expansión de la vacuna, la recuperación económica en Estados Unidos el primer trimestre del año y la presidencia de Joe Biden, que 
está propiciando la llegada de nuevos contingentes migratorios centroamericanos, resulta conveniente hacer una reflexión sobre el devenir que podrían tomar en meses venideros las políticas migratorias de control y de protección.

En primer lugar, cabe esperar que el control migratorio continúe predominando. Por más que el gobierno de Biden mantenga un discurso más favorable a la migración que la administración anterior, lo más probable es que se muestre partidaria de cualquier medida que pueda reducir la llegada de más migración irregular como lo han hecho otros gobiernos demócratas precedentes. En este sentido, no es de extrañar que la administración de Biden haya mantenido el esquema de bloquear los flujos migratorios en la frontera sur y regresarlos a México de acuerdo con el Título 42, en detrimento de la vulneración del derecho a solicitar asilo de la población extranjera que llega al territorio estadounidense. La terminación de los MPP, recibir a menores no acompañados y a ciertas familias con menores, etcétera, resultan medidas claramente insuficientes para revertir los pasos dados por la administración Trump en menoscabo del sistema de asilo estadounidense.

El gobierno estadounidense seguirá presionando - ya sea de un modo distinto al ejercido por el presidente Trump - para que México y los países de Centroamérica sigan realizando medidas de contención de los flujos migratorios. En este contexto, resulta muy improbable que la administración de López Obrador permita el libre tránsito hacia el territorio estadounidense; no obstante, como puede deducirse de las cifras de detenciones de las fuentes de los registros administrativos de Estados Unidos y México, los migrantes continúan intentando y logrando alcanzar el territorio estadounidense, aunque sea de manera irregular. En cualquier caso, el gobierno mexicano tiene la obligación moral y el deber legal de proteger a los migrantes centroamericanos - que durante la pandemia del COVID-19 están en circunstancias especialmente adversas - con el reforzamiento de su sistema de refugio, con programas ad hoc de entrega de TVRH y generando nuevas vías para inmigrar en México; todo ello para coadyuvar a una migración "ordenada, segura y regular", pues la gestión de la migración no debería reducirse a impedir la movilidad de las personas de menores recursos económicos. 


\section{REFERENCIAS BIBLIOGRÁFICAS}

ACNUR, (2020). Key Legal Considerations on Access to Territory for Persons in Need of International Protection in the Context of the COVID-19 Response, consultado el 3 de marzo de 2021, disponible en https://www.refworld. org/pdfid/5e7132834.pdf

ACNUR México, (2020). A pesar de las restricciones por la pandemia, las personas que huyen de la violencia y la persecución continúan solicitando asilo en México, consultado el 3 de marzo de 2021, disponible en https:// www.acnur.org/noticias/briefing/2020/4/5ea818924/a-pesar-delas-restricciones-por-la-pandemia-las-personas-que-huyen-de.html\# ga $=2.253285705 .1193552062 .1611858863-2091337423.1611858863$

Adamski, J. K., (2021). COVID-19 and Its Impacts on Migration - the Politics-Work-Violence Nexus, consultado el 3 de marzo de 2021, disponible en https://wladzasadzenia.pl/2020/18/covid-19-and-its-impacts-onmigration-the-politics-work-violence-nexus.pdf

AFP, (2021). Fuerzas de seguridad de Guatemala frenan caravana migrante con gas lacrimógeno y palos. El Economista, consultado el 3 de marzo de 2021, disponible en https://www.eleconomista.com.mx/internacionales/Fuerzas-de-seguridad-de-Guatemala-frenan-caravana-migrante-con-gas-lacrimogeno-y-palos-20210117-0007.html

Al Otro Lado et al., (2020). Carta al gobierno de México: es imperativo proteger los derechos de personas migrantes durante pandemia COVID-19, consultado el 3 de marzo de 2021, disponible en https://www.wola.org/ es/2020/04/carta-gobierno-mexico-derechos-humanos-migrantes-pandemia-covid-19/

Amnistía Internacional, Physicians for Human Rights, Latin America Working Group, Kids in Need of Defense, OXFAM y Haitian Bridge Alliance, (2020a). Explainer on U.S. Deportations and Expulsions During the COVID-19 Pandemic. Consultado el 3 de marzo de 2021, disponible en https://www.amnestyusa.org/wp-content/uploads/2020/05/Explainer-on-Deportations-and-Expulsions-During-the-COVID-19-Pandemic-1. pdf

Amnistía International, Refugees International, Human Rights First, Physicians for Human Rights, Women's Refugee Commission, Medecins Sans Frontieres, (2020b). Responding to the COVID-19 Crisis While Protecting Asylum Seekers, consultado el 3 de marzo de 2021, disponible en https://www.humanrightsfirst.org/sites/default/files/COVID-19\%20 Asylum\%20Statement-2_0.pdf

Anguiano Téllez, M. E. y Lucero Vargas, C., (2020). “La construcción gradual de la política de contención migratoria en México”, pp. 123-157, en Villafuerte Solís, D. y Anguiano Téllez, M. E. (coords.), Movilidad humana en tránsito: retos de la Cuarta Transformación en política migratoria, CLACSO, CESMECA-UNICACH, consultado el 3 de mayo de 2021, disponible en 
http://biblioteca.clacso.edu.ar/clacso/se/20200402045757/movilidad_ humana.pdf

Arango, J., (2005). "Dificultades y dilemas de la política de inmigración”, en Arbor, 181(713), 17-25, consultado el 29 de abril de 2021, disponible en http://dx.doi.org/10.3989/arbor.2005.i713.439

Arango, J., (2019). "Eficacia frente a principios: políticas de extrema dureza contra la inmigración y el asilo en Estados Unidos y Europa", en Anuario CIDOB de la Inmigración, 35-49, consultado el 3 de mayo de 2021, disponible en https://www.cidob.org/es/articulos/anuario_cidob_de_la_inmigracion/2019/eficacia_frente_a_principios_politicas_de_extrema_dureza_contra_la_inmigracion_y_el_asilo_en_estados_unidos_y_europa

Arévalo, A., (2021). “"Doblar muñecas.” De medidas sanitarias a la supresión inconstitucional de derechos ciudadanos en la gestión del COVID-19 en El Salvador", 189-218, en Arévalo, A. (coord.), COVID-19 Nuevas enfermedades, antiguos problemas en Centroamérica, CLACSO, consultado el 3 de mayo de 2021, disponible en http://biblioteca.clacso.edu. ar/clacso/gt/20210414053709/COVID-19-Nuevas-enfermedades-viejos-problemas.pdf

Argueta, C. N., (2016). Border Security: Immigration Enforcement Between Ports of Entry. Congressional Research Service, consultado el 1 de mayo de 2021, disponible en https://fas.org/sgp/crs/homesec/R42138. pdf

Arroyo, L., (2021). La frontera saturada: así llegó a la primera crisis migratoria de la era Biden. El País, consultado el 23 de marzo de 2021, disponible en https://elpais.com/mexico/2021-03-22/la-frontera-sur-saturada-asi-se-llego-a-la-primera-crisis-migratoria-de-la-era-biden.html

Ávalos Rivera, A. R. y Celecia Pérez, C., (2020). "El discurso oficial mexicano sobre la migración. Un análisis de las mañaneras de AMLO", en Revista Comunicación, 1(18), 99-118, consultado el 1 de mayo de 2021, disponible en http://dx.doi.org/10.12795/Comunicacion.2020.i18.06

Banulescu-Bogdan, N., Benton, M. y Fratzke, S., (2020). Coronavirus is Spreading Across Borders, But It Is Not a Migration Problem. Migration Policy Institute, consultado el 3 de marzo de 2021 en https://www.migrationpolicy.org/news/coronavirus-not-a-migration-problem

Barrios, L., (2021). “"No moriremos de COVID-19, sino de corrupción”", pp. 31-48, en Arévalo, A. (coord.), COVID-19 Nuevas enfermedades, antiguos problemas en Centroamérica, CLACSO, consultado el 3 de mayo de 2021, disponible en http://biblioteca.clacso.edu.ar/clacso/gt/20210414053709/ COVID-19-Nuevas-enfermedades-viejos-problemas.pdf

Basok, T., (2020). "Documentar a las personas migrantes en México: ¿Protegiendo a los vulnerables o disciplinando a los ingobernables?", 73-94, en Sandoval García, C. (ed.). Puentes, no muros. Contribuciones para una política progresista en migraciones, Argentina y México, CLACSO y Fun- 
dación Rosa Luxemburg, consultado el 29 de abril de 2021, disponible en http://biblioteca.clacso.edu.ar/clacso/se/20200327054129/Puentesno-muros.pdf

Becerril, A., (2020). Por COVID-19, ordenan liberar a migrantes; juez decreta darles la residencia temporal. Excelsior, consultado el 3 de marzo de 2021, disponible en https://www.excelsior.com.mx/nacional/ por-covid-19-ordenan-liberar-a-migrantes-juez-decreta-darles-residencia-temporal/1376772

Betts, A., (2013). Survival Migration: Failed Governance and the Crisis of Displacement. Cornell University Press. https://www.jstor.org/stable/10.7591/j.ctt32b5cd.6

Bleiker, C., (2020). Estados Unidos continúa deportando a centroamericanos con coronavirus. DW Made for Minds, consultado el 3 de marzo de 2021, disponible en https://p.dw.com/p/3chs4

Blue, S. A., Devine, J. A., Ruiz, M. P., McDaniel, K., Hartsell, A. R., Pierce, C. J., Johnson, M., Tinglov, A. K., Yang, M., Wu, X., Moya, S., Cross, E. y Starnes, C. A., (2021). "Im/Mobility at the US-Mexico Border during the COVID-19 Pandemic", en Social Sciences, 10(47), consultado el 3 de marzo de 2021, disponible en https://doi.org/10.3390/socsci10020047

Bojórquez, I., Infante, C., Vieitez, I., Larrea, S. y Santoro, C., (2020). "Migrants in Transit and Asylum Seekers in Mexico: An Epidemiological Analysis of the COVID-19 Pandemic", en medRXiv, consultado el 3 de marzo de 2021, disponible en http://doi.org/10.1101/2020.05.08.20095604

Bonilla, L. y Tovar, J., (2020). 'Nos da miedo ir al hospital'. Chicago Tribune, consultado el 1 de mayo de 2021, disponible en https://www.chicagotribune.com/espanol/sns-es-temor-visita-hospital-indocumentados-coronavirus-20200507-iu35myg7hnhb3asuqj7uyelnpu-story.html

Brito, M. O., (2020). “COVID-19 in the Americas: Who's Looking After Refugees and Migrants?", en Annals of Global Health, 86(1), 1-3, consultado el 3 de marzo de 2021, disponible en https://www.ncbi.nlm.nih.gov/pmc/ articles/PMC7333547/pdf/agh-86-1-2915.pdf

Bustamante, J. A., (2002). Migración internacional y derechos humanos. El Colegio de la Frontera Norte: México, consultado el 30 de abril de 2021, disponible en https://archivos.juridicas.unam.mx/www/bjv/libros/1/296/1.pdf

Calva Sánchez, L. E. y Torre Cantalapiedra, E., (2020). "Cambios y continuidades en la política migratoria durante el primer año del gobierno de López Obrador", en Norteamérica, 15(2), consultado el 30 de abril de 2021, disponible en http://dx.doi.org/10.22201/cisan.24487228e.2020.2.415

Capps, R., Meissner, D., Ruiz Soto, A. G., Bolter, J. y Pierce, S., (2019). From Control to Crisis Changing Trends and Policies Reshaping U.S.-Mexico Border Enforcement. Washington, DC: Migration Policy Institute, consultado el 1 de mayo de 2021, disponible en https://www.migrationpolicy.org/ 
research/changing-trends-policies-reshaping-us-mexico-border-enforcement

Caravanas migrantes, un riesgo para salud pública: SRE., (2020). La Silla Rota, consultado el 3 de marzo de 2021, disponible en https://lasillarota.com/nacion/caravanas-migrantes-un-riesgo-para-salud-publica-sre/443340

Cárdenas Solorio, A., (2020). Estados Unidos y el COVID-19 como pretexto para desaparecer el derecho al asilo. Nexos, consultado el 3 de marzo de 2021, disponible en https://eljuegodelacorte.nexos.com.mx/?p=11556

CBP (U.S. Customs and Border Protection), (2020). Patrulla Fronteriza fortalece su parecencia para combatir COVID-19, consultado el 3 de marzo de 2021, disponible en https://www.cbp.gov/newsroom/local-media-release/patrulla-fronteriza-fortalece-su-parecencia-para-combatir-covid-19

Cepal (Comisión Económica para América Latina y el Caribe), (2020). América Latina y El Caribe ante la pandemia del COVID-19. Efectos económicos y sociales, consultado el 3 de marzo de 2021, disponible en https:// repositorio.cepal.org/bitstream/handle/11362/45337/6/S2000264_es.pdf

Cepal, United Nations Network on Migration y OIM ,(Comisión Económica para América Latina y el Caribe, United Nations Network on Migration y Organización Internacional para las Migraciones), (2020). Revisión regional sobre la implementación del pacto mundial para la migración, segura, ordenada y regular en América Latina y El Caribe. Cuestionario para los Estados miembros. México, consultado el 3 de mayo de 2021, disponible en https://migrationnetwork.un.org/sites/default/files/docs/mexico.pdf

Cleaveland, C. y Waslin, M., (2021). COVID-19: Threat and Vulnerability Among Latina Immigrants. Affilia, consultado el 3 de marzo de 2021 en https://doi.org/10.1177\%2F0886109920985232

Comar, (Comisión Mexicana de Ayuda a Refugiados), (2020). Información importante ante el COVID-19, consultado el 3 de marzo de 2021, disponible en https://www.gob.mx/comar/galerias/informacion-importante-ante-el-covid-19?idiom=es

Comar, (Comisión Mexicana de Ayuda a Refugiados), (2021). Estadísticas Comar, consultado el 3 de marzo de 2021, disponible en https:// www.gob.mx/cms/uploads/attachment/file/604569/CIERRE_DICIEMBRE-2020_1-Ene-2021_.pdf

El Colef, (El Colegio de la Frontera Norte), (2018). La caravana de migrantes centroamericanos en Tijuana 2018. Diagnóstico y propuestas de acción, consultado el 22 de enero de 2021, disponible en https://www. colef.mx/estudiosdeelcolef/la-caravana-de-migrantes-centroamericanos-en-tijuana-2018-diagnostico-y-propuestas-de-accion 
Eller, J., Israel, E., Lugo, P. y Torre, J., (2020). Protocolos de Protección a Migrantes: Implementación y Consecuencias para los solicitantes de Asilo en México. Strauss Center for International Security and Law y FM4 Paso Libre, consultado el 3 de mayo de 2021, disponible en https://www. strausscenter.org/wp-content/uploads/PRP-218_-Protocolos-de-Proteccio\%CC\%81n-a-Migrantes-1.pdf

Ferguson, N. M., Laydon, D., Nedjati-Gilani, G., Imai, N., Ainslie, K., Baguelin, M., Bhatia, S., Boonyasiri, A., Cucunubá, Z., Cuomo-Dannenburg, G., Dighe, A., Dorigatti, I., Fu, H., Gaythorpe, K., Green, W., Hamlet, A., Hinsley, W., Okell, L. C., van Elsland, S., Thompson, H., Verity, R., Volz, E., Wang, H., Wang, Y., Walker, P. G. T., Walters, C., Winskill, P., Whittaker, C., Donnelly, C. A., Riley S. y Ghani, A. C., (2020). Impact of Non-Pharmaceutical Interventions (NPIs) to Reduce COVID-19 Mortality and Healthcare Demand, consultado el 3 de marzo de 2021, disponible en https://doi.org/10.25561/77482

Garibo García, M. G., (2016). "Migración centroamericana en tránsito por México en el marco de la externalización estadounidense: Plan Sur y Plan Frontera Sur", en PuntoCUNorte. Revista Académica del Centro Universitario del Norte, 3, 71-102. Consultado el 3 de marzo de 2021, disponible en http://www.cunorte.udg.mx/puntocunorte/revistas/3/articulos/migracion-centroamericana-en-transito-por-mexico-en-el-marco-de-la

Gelatt, J., (2020). Immigrant Workers: Vital to the U.S. COVID-19 Response, Disproportionately Vulnerable. Migration Policy Institute, consultado el 3 de marzo de 2021, disponible en https://www.migrationpolicy.org/ research/immigrant-workers-us-covid-19-response

González Díaz, M., (2021). Coronavirus: "En México no es que no hayan sabido que hacer con la pandemia, es que tomaron la decisión de no hacerlo". $B B C$, consultado el 3 de marzo de 2021, disponible en https://www. bbc.com/mundo/noticias-america-latina-56220420

Guadagno, L., (2020). Migrants and the COVID-19 Pandemic: An Initial Analysis. International Organization for Migration, consultado el 3 de marzo de 2021, disponible en https://publications.iom.int/system/files/ pdf/mrs-60.pdf

Guttentag, L., (2020). Coronavirus Border Expulsions: CDC's Assault on Asylum Seekers and Unaccompanied Minors. Just Security, consultado el 3 de marzo de 2021, disponible en https://www.justsecurity.org/69640/ coronavirus-border-expulsions-cdcs-assault-on-asylum-seekers-and-unaccompanied-minors /

Heyman, J. y Slack, J., (2018). Blockading Asylum Seekers at Ports of Entry at the US-Mexico Border Puts Them at Increased Risk of Exploitation, Violence, and Death. Center for Migration Studies, consultado el 1 de mayo de 2021, disponible en http://cmsny.org/publications/heyman-slackasylum-poe/\#_edn1

Hollifield, J. F., (2020). Migración y movilidad en época de pandemia. Migración y desigualdades ante COVID-19. El contexto económico, político y 
social en México y Estados Unidos, consultado el 3 de marzo de 2021, disponible en https://migdep.colmex.mx/publicaciones/COVID-19-Contexto-Economico-Politico-Social.pdf

INM, (Instituto Nacional de Migración), (2021a). Mantiene INM vigilancia en la frontera sur, consultado el 3 de marzo de 2021, disponible en https://www.gob.mx/inm/prensa/mantiene-inm-vigilancia-en-la-frontera-sur-261321

INM (Instituto Nacional de Migración), (2021b). El @INAMI_mx mantiene vigilancia en estados del sur de \#México, principalmente en Chiapas, Tabasco, Campeche y Quintana Roo, para hacer cumplir la Ley de Migración. Se trabajacon @GN_MEXICO_, @SEDENAmx y @SEMAR_mx, a fin de mantener un tránsito seguro, ordenado y regular, consultado el 3 de marzo de 2021, disponible en https://twitter.com/INAMI_mx/ status 1349815375953883136 ?ref_src $=$ twsrc $\% 5$ Etfw\% 7 Ctwcamp\%5Etweetembed\%7Ctwterm\%5E1349815375953883136\%7Ctwgr\%5E\%7Ctwcon\%5Es1_c10\&ref_url=https\%3A\%2F\%2F

Irías, G., Vijil, L. y López, B., (2021). "COVID-19 en Honduras. El colapso sanitario y el virus autoritario", pp. 189-218, en Arévalo, A. (coord.), COVID-19 Nuevas enfermedades, antiguos problemas en Centroamérica, CLACSO, consultado el 3 de mayo de 2021, disponible en http://biblioteca.clacso.edu.ar/clacso/gt/20210414053709/COVID-19-Nuevas-enfermedades-viejos-problemas.pdf

Irvine, M., Coombs, D., Skarha, J., del Pozo, B., Rich, J., Taxman, F. y Green, T. C., (2020). "Modeling COVID-19 and Its Impacts on U.S. Immigration and Customs Enforcement (ICE) Detention Facilities, 2020", en Journal of Urban Health, consultado el 3 de marzo de 2021, disponible en https://doi. org/10.1007/s11524-020-00441-x

Isacson, A., (2020). La agenda de inmigración de Trump se revela completamente con el COVID-19 y amenaza muchas vidas. Brújula ciudadana, consultado el 3 de marzo de 2021, disponible en https://www.revistabrujula.org/agenda-de-inmigracion-de-trump-se-r

Isacson, A., Beltrán, A., Pachico, E., Moreno, M. y Meyer, M., (2020). Al menos que los Estados Unidos implemente estas 5 estrategias regionales de migración, el COVID-19, podría presagiar otra crisis humanitaria en nuestra frontera. WOLA, consultado el 3 de marzo de 2021, disponible en https://www.wola.org/es/analisis/5-estrategias-regionales-migracion-covid-19-estados-unidos/

Isfer, A., (2020). Estados Unidos, el nuevo foco de la pandemia. La Vanguardia, consultado el 2 de mayo de 2021, disponible en https://www. lavanguardia.com/vida/junior-report/20200415/48499414926/covid19-coronavirus-estados-unidos-contagios.html

Khuner, G., (2020). Las organizaciones mexicanas de derechos humanos actúan para la protección de migrantes durante la pandemia de COVID-19. Migración y desigualdades ante COVID-19. El Contexto económico, político 
y social en México y Estados Unidos, consultado el 3 de marzo de 2021, disponible en https://migdep.colmex.mx/publicaciones/COVID-19-Contexto-Economico-Politico-Social.pdf

LM (Ley de Migración), (2017). Ley de Migración y reformas posteriores, Diario Oficial, México. Consultado el 3 de marzo de 2021, disponible en http://www.diputados.gob.mx/LeyesBiblio/ref/lmigra/LMigra_ ref06_09nov17.pdf

McKee Irwin, R. y Del Monte Madrigal, J. A., (2020). COVID-19 y la vulnerabilidad de las personas migrantes en Tijuana: una crisis inminente. Observatorio de Legislación y Política Migratoria, consultado el 3 de marzo de 2021, disponible en https://observatoriocolef.org/wp-content/uploads/2020/04/covidTJ-espanol.pdf

Meer, N. y Villegas, L., (2020). The Impact of COVID-19 on Global Migration. Governance of the Local Integration of Migrants and Europe's Refugees, consultado el 3 de marzo de 2021, disponible en https:// www.glimer.eu/wp-content/uploads/2020/06/Global-Migration-Policies-and-COVID-19.pdf

Milenio Digital, (2020). Es improbable que migrantes contribuyan a problema de salud pública: López-Gatell. Milenio, consultado el 3 de marzo de 2021, disponible en https://www.milenio.com/politica/lopez-gatell-gobierno-mexico-atendera-caravana-migrante

Naciones Unidas, (2020). Documento de políticas del Secretario General sobre la COVID-19 y las personas en movimiento, consultado el 3 de marzo de 2021, disponible en https://www.un.org/sites/un2.un.org/files/ sg_brief_c19_people_on_the_move_spanish.pdf

Naciones Unidas, Asamblea General, (2015). Protección de los derechos humanos de los migrantes: migrantes en tránsito, consultado el 1 de mayo de 2021, disponible en https://www.acnur.org/fileadmin/Documentos/ BDL/2015/10161.pdf

Naranjo Giraldo, G. E., (2014). "Desterritorialización de fronteras y externalización de políticas migratorias. Flujos migratorios irregulares y control de las fronteras exteriores en la frontera España-Marruecos", en Estudios Políticos, núm. 45, pp. 13-32, consultado el 3 de marzo de 2021, disponible en https://orcid.org/0000-0002-6270-1713

OIM (Organización Internacional para las Migraciones), (2020). Cross-Border Human Mobility Amid and After Covid-19, consultado el 3 de marzo de 2021, disponible en https://www.iom.int/sites/default/files/defaul/ pp_cross-border_human_mobility_amid_and_after_covid-19_policy.pdf

Pachico, E. y Meyer, M., (2020). Un año después del acuerdo migratorio entre los Estados Unidos y México, es claro que generó un desastre humanitario. WOLA, consultado el 3 de marzo de 2021, disponible en https:// www.wola.org/es/analisis/acuerdo-migratorio-estados-unidos-mexico-genero-desastre-humanitario/ 
París Pombo, M. D., (2016). "Políticas migratorias restrictivas y violencia institucional contra los migrantes", en Ecuador Debate, núm. 97, pp. 85102, consultado el 1 de mayo de 2021, disponible en https://repositorio.flacsoandes.edu.ec/xmlui/bitstream/handle/10469/12124/REXTNED97-07-Paris.pdf?sequence=1\&isAllowed=y

Peters, M. de J., (2020). Ejército, GN y Migración sellan la frontera sur. El Universal, consultado el 21 de diciembre de 2020, disponible en https://www.eluniversal.com.mx/estados/ejercito-gn-y-migracion-sellan-la-frontera-sur

Pierce, S. y Bolter, J., (2020). Dismantling and Reconstructing the U.S. Immigration System: A Catalog of Changes under the Trump Presidency. Migration Policy Institute, consultado el 3 de marzo de 2021, disponible en https://www.migrationpolicy.org/research/us-immigration-system-changes-trump-presidency

Ramírez-García, T. y Lozano Ascensio, F., (2021). "Vulnerabilidad de la población migrante de México frente a la pandemia de COVID-19", en Revista Latinoamericana de Población, 15(28), 102-134, consultado el 3 de mayo de 2021, disponible en https://doi.org/10.31406/relap2021.v15. i1.n28.4

Reglamento Ley de Migración, (RLM). (2014). Reglamento de la Ley de Migración y reformas posteriores, Diario Oficial, México, consultado el 3 de marzo de 2021, disponible en www.diputados.gob.mx

Reina, E., (2020). Guatemala toma el relevo de México para frenar las caravanas de migrantes. El País, consultado el 3 de marzo de 2021, disponible en https://elpais.com/mexico/2020-10-06/guatemala-toma-el-relevo-de-mexico-para-frenar-las-caravanas-de-migrantes.html

Ruiz Soto, A. G., (2020). Un año después del Acuerdo Estados Unidos-México. La transformación de las políticas migratorias mexicanas. Migration Policy Institute, consultado el 3 de marzo de 2021, disponible en https:// www.migrationpolicy.org/research/un-ano-acuerdo-estados-unidos-mexico

Sanchez, G. y Achilli, L., (2020). Stranded: The Impacts of COVID-19 on Irregular Migration and Migrant Smuggling. Migration Policy Centre, consultado el 3 de marzo de 2021, disponible en https://cadmus.eui.eu/handle/1814/67069

Segob, UPMRIP e INM (Secretaría de Gobernación, Unidad de Política Migratoria, Registro e Identidad de personas e Instituto Nacional de Migración), (2021). Boletines mensuales de estadísticas migratorias, consultado el 3 de marzo de 2021, disponible en http://www.politicamigratoria. gob.mx/es_mx/SEGOB/Boletines_Estadisticos.

Sirkeci, I. y Yüceşahin, M. M., (2020). "Coronavirus and Migration: Analysis of Human Mobility and the Spread of COVID-19", en Migration Letters, 
17(2), 379-398, consultado el 3 de marzo de 2021, disponible en https:// orcid.org/0000-0002-2334-7424

SRE (Secretaría de Relaciones Exteriores), (2021). México exhorta a cumplir protocolos migratorios y sanitarios establecidos en la gestión de flujos masivos irregulares de personas migrantes, consultado el 3 de marzo de 2021, disponible en https://www.gob.mx/sre/prensa/mexico-exhorta-a-cumplir-con-protocolos-migratorios-y-sanitarios-establecidos-en-la-gestion-de-flujos-masivos-irregulares-de-personas-migrantes-procedentes-de-honduras

Slack, J. y Heyman, J., (2020). "Asylum and Mass Detention at the U.S.-Mexico Border during Covid-19", en Journal of Latin American Geography, vol. 19(3), 334-339, consultado el 7 de mayo de 2021, disponible en https:// doi.org/10.1353/lag.2020.0057

Torre Cantalapiedra, E., (2021). "Las tarjetas de visitante por razones humanitarias: una política migratoria de protección ¿e integración?”, en Entre Diversidades, 8(2).

Torre Cantalapiedra, E. y Mariscal Nava, D. M., (2020). "Batallando con fronteras: estrategias migratorias en tránsito de participantes en caravanas de migrantes", en Estadios Fronterizos, 12, 1-21, consultado el 29 de abril de 2021, disponible en https://doi.org/10.21670/ref.2005047

Torre Cantalapiedra, E., París Pombo, M. D. y Gutiérrez López, E. E., (2021). "El sistema de refugio mexicano: entre proteger y contener", en Frontera Norte, 33, 1-26, consultado el 28 de abril de 2021, disponible en https:// fronteranorte.colef.mx/index.php/fronteranorte/article/view/2103

Tucker, D. y Pindado, E., (2020). Llueve sobre mojado en Honduras: El devastador impacto de los huracanes Eta e Iota. Amnistía Internacional, consultado el 3 de marzo de 2021, disponible en https://www.amnesty. org/es/latest/news/2020/12/d evastating-impact-hurricanes-eta-iota-honduras/

Universidad Johns Hopkins, (2021). COVID-19 Dashboard by the Center for Systems Science and Engineering (CSSE) at Johns Hopkins University (JHU), consultado el 11 de marzo de 2021, disponible en https://coronavirus. jhu.edu/map.html

U.S. Customs and Border Protection (2020a). Nationwide Enforcement Encounters: Title 8 Enforcement Actions and Title 42 Expulsions, consultado el 3 de marzo de 2021, disponible en https://www.cbp.gov/newsroom/ stats/cbp-enforcement-statistics/title-8-and-title-42-statistics

U.S. Customs and Border Protection, (2020b). FY 2020 Nationwide Enforcement Encounters: Title 8 Enforcement Actions and Title 42 Expulsions, consultado el 3 de marzo de 2021, disponible en https://www.cbp.gov/ newsroom/stats/cbp-enforcement-statistics/title-8-and-title-42-statistics-fy 2020 
U.S. Department of State, (2019). U.S.-Mexico Joint Declaration, consultado el 1 de mayo de 2021, disponible en https://www.state.gov/u-s-mexicojoint-declaration/\#.XPsRhN_2nRA.twitter

U.S. DHHS, CDC, (U.S. Department of Health and Human Service Center for Disease Control and Prevention) (2020). Order Suspending the Right to Introduce Certain Persons from Countries Where a Quarantinable Communicable Disease Exists, consultado el 1 de mayo de 2021, disponible en https://www.cdc.gov/coronavirus/downloads/10.13.2020-CDC-Order-Prohibiting-Introduction-of-Persons-FINAL-ALL-CLEAR-encrypted. pdf

Valle, V. M. y Deschak, C. I., (2021). "La salud de los migrantes y sujetos de protección internacional centroamericanos en México ante el COVID-19. Marco legal versus acceso real", 121-148, en Arévalo, A. (coord.), COVID-19 Nuevas enfermedades, antiguos problemas en Centroamérica, CLACSO, consultado el 3 de mayo de 2021, disponible en http://biblioteca.clacso.edu. ar/clacso/gt/20210414053709/COVID-19-Nuevas-enfermedades-viejos-problemas.pdf

Velasco, L., Coubes, M. L., Contreras, O. F., Bojórquez, I., Contreras, C., García, H., Lares, F. y Rodríguez, E., (2020). Los jornaleros agrícolas migrantes. Documentos de Contingencia, consultado el 3 de marzo de 2021, disponible en https://www.colef.mx/estudiosdeelcolef/los-jornaleros-agricolas-migrantes/

Yee Quintero, J. C. y Torre Cantalapiedra, E., (2016). "Lidiando con la frontera vertical: estrategias migratorias de los hondureños en tránsito por México" en REMHU: Revista Interdisciplinar da Mobilidade Humana, XXIV(47), 97-114, consultado el 7 de mayo de 2021, disponible en https:// doi.org/10.1590/1980-85852503880004707

\section{RESUMEN CURRICULAR DEL AUTOR}

\section{Eduardo Torre Cantalapiedra}

Doctor en Estudios de Población por El Colegio de México. Maestro en Relaciones Económicas Internacionales y Cooperación por la Universidad de Guadalajara. Posee las licenciaturas en Derecho; en Administración y Dirección de Empresas; y en Ciencias Políticas por la Universidad Complutense de Madrid. Actualmente es Investigador de Cátedras Conacyt en El Colegio de la Frontera Norte e imparte docencia en la Universidad Nacional Autónoma de México. Pertenece al Sistema Nacional de Investigadores, Nivel I. Es autor de más de 40 artículos en revistas arbitradas e indexadas. Entre sus publicaciones más recientes se encuentra el libro Caravanas: sus protagonistas ante 
las políticas migratorias, 2021, editado por El Colegio de la Frontera Norte y el artículo "El sistema de refugio mexicano: entre proteger y contener", Frontera Norte, 2021, en coautoría con María Dolores París Pombo y Eduardo Elías Gutiérrez López.

Dirección electrónica: etorre@colef.mx

Orcid: https://orcid.org/0000-0002-4074-3752 